\title{
Laparoscopic versus open surgery for rectal cancer: Results of a systematic review and meta-analysis on clinical efficacy
}

\author{
JUN-KANG ZHAO* , NAN-ZHENG CHEN* , JIAN-BAO ZHENG, SAI HE and XUE-JUN SUN \\ Department of General Surgery, The First Affiliated Hospital of Medical College of Xi'an Jiaotong University, \\ Xi'an, Shaanxi 710061, P.R. China
}

Received February 11, 2014; Accepted July 2, 2014

DOI: $10.3892 / \operatorname{mco} .2014 .345$

\begin{abstract}
Colorectal cancer is one of the main malignant tumors threatening human health. Surgery plays a pivotal role in treating colorectal cancer. The present study aimed to compare the clinical effect in patients with rectal cancer undergoing laparoscopic versus open surgery by meta-analysis of the randomized controlled trials (RCTs) published in the past 20 years. The data showed that 14 RCTs comparing laparoscopic surgery with conventional open surgery for rectal cancer matched the selection criteria and reported on 2,114 subjects, of whom 1,111 underwent laparoscopic surgery and 1,003 underwent open surgery for rectal cancer. Blood loss $(\mathrm{P}<0.00001)$, days to passage of flatus $(\mathrm{P}=0.0003)$, first bowel movement $(\mathrm{P}=0.0006)$, fluids intake $(\mathrm{P}<0.00001)$, walking independently $(\mathrm{P}<0.00001)$, length of hospital duration $(\mathrm{P}=0.003)$ and the rate of wound infection $(\mathrm{P}=0.04)$ were all significantly reduced following laparoscopic surgery. The incidence of complications, such as ureteric injury $(\mathrm{P}=0.33)$, urinary retention $(\mathrm{P}=0.43)$, ileus $(\mathrm{P}=0.05)$, anastomotic leakage $(\mathrm{P}=0.09)$ and incisional hernia $(\mathrm{P}=0.88)$, were not significantly different between the two groups. There were no significant differences in lymph nodes harvested $(\mathrm{P}=0.88)$, length of specimen $(\mathrm{P}=0.60)$, circumferential resection margin $(\mathrm{CRM})(\mathrm{P}=0.86)$, regional recurrence $((\mathrm{P}=0.08)$, port site or wound metastasis $(\mathrm{P}=0.67)$, distant metastasis $(\mathrm{P}=0.12)$, 3-year overall survival $(\mathrm{OS})(\mathrm{P}=0.42), 3$-year disease-free survival (DFS) $(\mathrm{P}=0.44), 5$-year $\mathrm{OS}(\mathrm{P}=0.60)$ and 5-year DFS $(\mathrm{P}=0.70)$. Therefore, laparoscopy for the treatment of patients with rectal cancer has the advantage of recovery and the same
\end{abstract}

Correspondence to: Professor Xue-Jun Sun, Department of General Surgery, The First Affiliated Hospital of Xi'an Jiaotong University, 277 Yanta West Road, Xi'an, Shaanxi 710061, P.R. China E-mail: sxjsky@aliyun.com

*Contributed equally

Key words: rectal cancer/surgery, laparoscopy, laparotomy, randomized controlled trial, meta-analysis complications and prognosis as laparotomy, which indicates that laparoscopy may provide a potential survival benefit for patients with rectal cancer.

\section{Introduction}

Colorectal cancer (CRC) is the third commonly diagnosed malignancy and leading cause of cancer-related mortality. More than 1.2 million patients are diagnosed with colorectal cancer each year. The mortality rate is decreased by $2-3 \%$ annually (1) owing to improvements in treatment. Despite the notable progress achieved in the treatment of colorectal cancer, surgery remains the best management for patients, compared to chemotherapy, radiation and even target therapy. Open surgery used to be the only option available, however, laparoscopic resection has developed as an alternative. Compared to open surgery, laparoscopic surgery has advantages, including reduced blood loss during surgery, slight pain, faster postoperative recovery and it does not affect the appearance of the skin following the surgery. Therefore, it has been rapidly applied to the surgical treatment of a variety of benign and malignant diseases. With regards to colorectal cancer surgery, certain randomized controlled trials (RCTs) have confirmed the safety and long-term effects of laparoscopic surgery $(2,3)$. The present study conducted a meta-analysis of laparoscopic surgery RCTs in treating rectal cancer compared to laparotomy between January 1991 and December 2012 to evaluate the clinical effect of laparoscopic surgery.

\section{Materials and methods}

Literature retrieval. Published literature between January 1991 and December 2012 on RCTs comparing laparoscopic and traditional open surgery in the treatment of rectal cancer was retrieved. The searchable database was PubMed and the key words were colorectal neoplasms, colorectal cancer, rectal neoplasms, rectal cancer, laparoscopy, laparoscopic and randomized controlled trial. In order to ensure the recall rate and to maximize the sample size, the retrieval method of combining the keywords with free words was used. Subsequent to retrieving the titles, full texts were downloaded 
and printed and when necessary the studies were obtained from the authors.

Inclusion criteria. The following criteria were identified for inclusion in the analysis: i) RCT comparing laparoscopic to open group in the treatment of colorectal or rectal cancer; ii) recording at least one of the following: Surgical data, the number of dissected lymph nodes, postoperative recovery, complications and prognosis; and iii) language was limited to English and Chinese.

Exclusion criteria. Exclusion from the study was determined as follows: i) Non-RCT; ii) for inflammatory bowel disease, emergency surgery was performed due to intestinal perforation or obstruction; iii) palliative surgery; and iv) study was lacking the required research data.

Evaluation of literature quality. The risk of bias table was used for quality evaluation. With reference to the recommended methods of 'The Cochrane Collaboration's tool for assessing risk of bias' in the Cochrane Handbook (4), seven indicators of RCT were analyzed and evaluated: Random sequences generating, allocation concealment, blinding of participants and implementers, blinding of outcome evaluation, incomplete result data studies, selective studies and bias from other sources.

Data extraction. The table was used to extract relevant data in the studies and when repetitive data were published by the same author or institution, the latest study was selected. Extraction indicators included: i) Baseline data, such as age, gender, American Society of Anesthesiologists grade, body mass index (BMI; $\left.\mathrm{kg} / \mathrm{m}^{2}\right)$, the ratio of tumor stage II-III (tumor-node metastasis), tumor location (the distance from the lower end of the tumor to the anal verge; $\mathrm{cm}$ ), history of abdominal surgery and anterior resection ratio. ii) Surgical data included surgery time ( $\mathrm{min}$ ), the cases of blood transfusion, the amount of blood loss (ml) during surgery, specimen length $(\mathrm{cm})$, the number of dissected lymph nodes, tumor location (the distance from the lower end of the tumor to the lower resection margin; $\mathrm{cm}$ ) and the positive rate of circumferential resection margin (CRM). iii) Postoperative recovery included the first exhaust time (day), the first intestinal peristalsis time (day), the first time of consuming liquid food (day), the time of independent ambulation (day) and the hospital duration (day). iv) Complications included ureteral injury, urinary retention, intestinal obstruction, anastomotic leakage, wound infection and incisional hernia. v) Prognosis included local recurrence rate, distant recurrence rate, incision or puncture implantation metastasis rate, 3-year overall survival (OS), 3-year disease-free survival (DFS), 5-year OS and 5-year DFS.

Statistical analysis. For the binary variables, the relative risk or odds ratio was obtained as the combined statistics; for the continuous variables, the weighted mean difference was obtained as the combined statistics; and for the survival rate, hazard ratio (HR) was acquired as the combined statistics. All the three variables were expressed with point estimation, $95 \%$ confidence intervals and the test level was $\mathrm{P}<0.05$. $\mathrm{P}<0.05$ was considered to indicate a statistically significant difference. Funnel plot analysis was employed for the potential publication bias. Prior to merging the statistics, $\chi^{2}$ test was used to first test for heterogeneity, the fixed-effect model was used if there was homogeneity and the random-effect model was used if the heterogeneity was significant $(\mathrm{P} \leq 0.1)$. The method introduced by Hozo et al (5) was used to extract the standard deviation (SD) and variance for the studies with median and range continuous variables, and $\log (\mathrm{HR})$ and standard error were extracted with the method by Tierney et al (6). The continuous variables only provided four quantile so that the mean and SD could not be extracted and these were excluded. The statistical analysis was performed using the Cochrane Collaboration's Review Manager 5.1 software (4).

\section{Results}

Evaluation of included literature quality and general data. A total of 14 RCTs were selected for the meta-analysis, including one in Chinese and 13 in English, three multicenter studies and 11 single-center studies. The study by Jayne et al (7) was a 3-year follow-up result of the study by Guillou et al (8). The literature quality evaluation is shown in Table I. The number of statistical cases in the laparoscopic group was 1,111 patients and in the open group it was 1,003. The statistical baseline data, including age, male ratio, anesthesia grade, BMI and other indicators, were relatively balanced (Table II).

Surgical data. The meta-analysis showed that compared to the open group, surgical time was prolonged for $31.42 \mathrm{~min}$, the amount of blood loss during the surgery was reduced by $108.95 \mathrm{ml}$ and the proportion of blood transfusion was reduced in the laparoscopic group, and the differences were statistically significant $(\mathrm{P}<0.05)$. However, there was no significant difference in the specimen length, the number of dissected lymph nodes, the distance from the lower end of the tumor to the resection margin and the CRM-positive rate $(\mathrm{P}>0.05)$ (Table III) (Fig. 1A and B).

Postoperative recovery. The meta-analysis showed that for the postoperative recovery in the laparoscopic group, the first exhaust time was 0.32 days earlier, the intestinal peristalsis time was 0.94 days earlier, the time of consuming liquid food was 1.04 days earlier, the independent ambulation time was 0.69 days earlier, the hospital duration was reduced by 2.66 days compared to that of the open group and the differences were statistically significant $(\mathrm{P}<0.05)$ (Table III).

Postoperative complications. The meta-analysis showed that the wound infection rate in the laparoscopic group was significantly lower compared to the open group, and there was no significant difference in ureteral injury, urinary retention, intestinal obstruction, anastomotic leakage and incisional hernia between the two groups (Table III).

Prognosis. The meta-analysis showed that there was no statistical difference in local recurrence, distant metastasis, incision or puncture implantation metastasis, 3-year OS, 3-year DFS, 5-year OS and 5-year DFS between the laparoscopic and the open groups ( $\mathrm{P}>0.05)$ (Table III) (Fig. 1C). 
Table I. Quality evaluation of the studies.

\begin{tabular}{|c|c|c|c|c|c|c|c|c|}
\hline Authors & $\begin{array}{c}\text { Publication } \\
\text { year }\end{array}$ & $\begin{array}{c}\text { Random } \\
\text { sequence } \\
\text { generation }\end{array}$ & $\begin{array}{c}\text { Allocation } \\
\text { concealment }\end{array}$ & $\begin{array}{l}\text { Outcome } \\
\text { evaluation } \\
\text { blinding }\end{array}$ & $\begin{array}{c}\text { Incomplete } \\
\text { outcome } \\
\text { data }\end{array}$ & $\begin{array}{l}\text { Selective } \\
\text { studies }\end{array}$ & $\begin{array}{l}\text { Other } \\
\text { biases }\end{array}$ & (Refs.) \\
\hline Araujo et al & 2003 & $?$ & $?$ & $?$ & $?$ & + & - & (9) \\
\hline Zhou et al & 2004 & $?$ & $?$ & $?$ & $?$ & $?$ & - & $(10)$ \\
\hline Guillou et al & 2005 & + & + & $?$ & + & + & + & $(8)$ \\
\hline Arteaga González et al & 2006 & $?$ & $?$ & $?$ & + & + & - & (11) \\
\hline Braga et al & 2007 & + & + & - & + & + & + & (12) \\
\hline Pechlivanides et al & 2007 & + & $?$ & $?$ & + & + & + & (13) \\
\hline Jayne et al & 2007 & + & + & $?$ & + & + & + & (7) \\
\hline Pan et al & 2007 & + & + & $?$ & + & + & - & (14) \\
\hline $\mathrm{Ng}$ et al & 2008 & + & + & $?$ & + & + & $?$ & (15) \\
\hline Lujan et al & 2009 & + & + & $?$ & + & + & + & (16) \\
\hline $\mathrm{Ng}$ et al & 2009 & + & + & $?$ & + & + & $?$ & (17) \\
\hline Kang et al & 2010 & + & + & $?$ & + & + & + & $(18)$ \\
\hline Liang et al & 2011 & + & + & + & + & - & - & (19) \\
\hline Veenhof et al & 2011 & $?$ & $?$ & + & + & + & - & $(20)$ \\
\hline
\end{tabular}

+ , low risk of bias; -, high risk of bias; ?, unknown risk.

Table II. Clinicopathological features of patients in the two groups.

\begin{tabular}{|c|c|c|c|c|c|c|c|}
\hline \multirow[b]{2}{*}{ Indicators } & \multirow[b]{2}{*}{$\mathrm{RCT}$} & \multirow{2}{*}{$\begin{array}{l}\text { Laparoscopic } \\
\text { group, } \mathrm{n}\end{array}$} & \multirow{2}{*}{$\begin{array}{l}\text { Open } \\
\text { group, } \mathrm{n}\end{array}$} & \multicolumn{2}{|c|}{ Heterogeneity test } & \multirow{2}{*}{$\begin{array}{l}\text { Combined effect size } \\
(95 \% \mathrm{CI})\end{array}$} & \multirow[b]{2}{*}{ P-value } \\
\hline & & & & Q & P-value & & \\
\hline Age & 11 & 836 & 857 & 8.96 & 0.54 & WMD $-0.25(-1.34$ to 0.84$)$ & 0.65 \\
\hline Male ratio & 12 & 858 & 875 & 9.29 & 0.59 & RR -0.25 (-1.34 to 0.84$)$ & 0.79 \\
\hline ASA I-II & 3 & 293 & 291 & 0.33 & 0.85 & RR 1.01 (0.95 to 1.07$)$ & 0.79 \\
\hline BMI & 3 & 203 & 205 & 3.35 & 0.19 & WMD $-0.20(-0.85$ to 0.44$)$ & 0.54 \\
\hline TNM II-III ratio & 3 & 664 & 682 & 9.83 & 0.46 & RR 0.99 (0.95 to 1.03$)$ & 0.66 \\
\hline Tumor location & 6 & 384 & 387 & 24.85 & 0.0001 & WMD $-0.13(-0.88$ to 0.62$)$ & 0.74 \\
\hline History of abdominal surgery & 5 & 120 & 112 & 1.97 & 0.74 & RR 1.09 (0.88 to 1.34$)$ & 0.43 \\
\hline Anterior resection ratio & 12 & 760 & 698 & 7.51 & 0.48 & RR 1.00 (0.95 to 1.04$)$ & 0.83 \\
\hline
\end{tabular}

RCT, randomized controlled trial; 95\% CI, 95\% confidence interval; WMD, weighted mean difference; RR, relative risk; ASA, American Society of Anesthesiologists; BMI, body mass index; TNM, tumor-node metastasis.

\section{Discussion}

Colorectal cancer ranks second in the number of cancer mortalities in Western countries (21). With the change to the diet structure, especially high-fat diet, the incidence rate of colorectal cancer continues to rise in China and the patients show a younger age trend. In recent years, a study has reported that the incidence rate of colorectal cancer in young patients continued to rise (22). Thus far, surgery remains the primary means for colorectal cancer treatment. Laparoscopic surgery of colorectal cancer has been applied for more than 20 years. Single-center RCTs of laparoscopic surgery for the treatment of colorectal cancer compared to traditional open surgery have been reported in China, however, multicenter RCTs are limited.
The pelvic anatomy space is narrow and therefore, exposure and manipulation for traditional open surgery are difficult. As one direction for the future development of minimally invasive surgery, laparoscopic technology not only increases the surgical field, but also has more advantages for low pelvic or even ultra-low presacral anastomosis. Laparoscopic technology can significantly increase the rate of anal preservation and thus improve the life quality of patients. The meta-analysis showed that the laparoscopic group had clear advantages, including less bleeding during surgery, faster postoperative recovery and shorter hospital duration. However, concerns remain regarding the radical curative effect of complete tumor resection, lymph node dissection and puncture implantation metastasis by laparoscopic surgery (23). The number of dissected lymph nodes is an important indicator in evaluating the radical curative 
Table III. Meta-analysis results for the surgical data, postoperative recovery and prognosis.

\begin{tabular}{|c|c|c|c|c|c|c|c|}
\hline \multirow[b]{2}{*}{ Indicators } & \multirow[b]{2}{*}{$\mathrm{RCT}$} & \multirow{2}{*}{$\begin{array}{l}\text { Laparoscopic } \\
\text { group, } n\end{array}$} & \multirow{2}{*}{$\begin{array}{l}\text { Open } \\
\text { group, } \mathrm{n}\end{array}$} & \multicolumn{2}{|c|}{ Heterogeneity test } & \multirow{2}{*}{$\begin{array}{l}\text { Combined effect size } \\
\qquad(95 \% \mathrm{CI})\end{array}$} & \multirow[b]{2}{*}{ P-value } \\
\hline & & & & $\mathrm{Q}$ & P-value & & \\
\hline \multicolumn{8}{|l|}{ Surgical data } \\
\hline Surgical time & 10 & 811 & 821 & 72.75 & $<0.00001$ & WMD 31.42 (19.75 to 43.08$)$ & $<0.00001$ \\
\hline Blood transfusion cases & 5 & 455 & 464 & 1.64 & 0.80 & OR $0.28(0.15$ to 0.50$)$ & $<0.0001$ \\
\hline Blood loss amount & 9 & 642 & 647 & 37.52 & $<0.00001$ & WMD $-108.95(-142.50$ to -75.41$)$ & $<0.00001$ \\
\hline Specimen length & 3 & 211 & 212 & 4.35 & 0.11 & WMD 0.12 (-0.34 to 0.59$)$ & 0.60 \\
\hline Lymph node & 9 & 593 & 601 & 8.94 & 0.35 & WMD 0.05 (-0.63 to 0.73$)$ & 0.88 \\
\hline $\begin{array}{l}\text { Distance from incised } \\
\text { edge to tumor }\end{array}$ & 2 & 189 & 194 & 19.36 & $<0.0001$ & WMD 1.10 (-0.77 to 2.97$)$ & 0.25 \\
\hline CRM-positive rate & 6 & 45 & 29 & 1.33 & 0.93 & RR 1.14 (0.66 to 1.64$)$ & 0.86 \\
\hline \multicolumn{8}{|l|}{ Postoperative recovery time } \\
\hline First exhaust & 3 & 257 & 259 & 3.44 & 0.18 & WMD $-0.32(-0.49$ to -0.14$)$ & 0.0003 \\
\hline Intestinal peristalsis & 5 & 398 & 408 & 28.12 & $<0.0001$ & WMD $-0.94(-1.48$ to -0.4$)$ & 0.0006 \\
\hline Consuming liquid food & 4 & 354 & 368 & 36.70 & $<0.00001$ & WMD -1.04 (-1.77 to -0.32$)$ & $<0.005$ \\
\hline Independent ambulation & 4 & 333 & 336 & 3.92 & 0.27 & WMD -0.69 (-0.87 to -0.51$)$ & $<0.00001$ \\
\hline Hospital duration & 8 & 472 & 477 & 33.42 & 0.0001 & WMD $-2.66(-4.40$ to -0.91$)$ & 0.003 \\
\hline \multicolumn{8}{|l|}{ Postoperative complications } \\
\hline Ureteral injury & 6 & 544 & 425 & 5.74 & 0.22 & OR 0.59 (0.20 to 1.70$)$ & 0.33 \\
\hline Urinary retention & 8 & 34 & 28 & 3.81 & 0.80 & OR 1.23 (0.73 to 2.08$)$ & 0.43 \\
\hline Intestinal obstruction & 10 & 811 & 821 & 9.48 & 0.39 & OR 0.64 (0.41 to 0.99$)$ & 0.05 \\
\hline Anastomotic leakage & 7 & 21 & 34 & 4.09 & 0.66 & OR 0.63 (0.36 to 1.08$)$ & 0.09 \\
\hline Wound infection & 9 & 59 & 64 & 8.42 & 0.39 & OR 0.68 (0.46 to 0.99$)$ & 0.04 \\
\hline Incisional hernia & 4 & 192 & 197 & 4.15 & 0.25 & OR 0.93 (0.38 to 2.29 ) & 0.88 \\
\hline \multicolumn{8}{|l|}{ Prognosis } \\
\hline Local recurrence & 5 & 239 & 238 & 1.64 & 0.80 & OR 0.44 (0.17 to 1.09$)$ & 0.08 \\
\hline Distant metastasis & 4 & 245 & 239 & 0.61 & 0.89 & OR 0.61 (0.32 to 1.14$)$ & 0.12 \\
\hline $\begin{array}{l}\text { Incision or puncture } \\
\text { implantation }\end{array}$ & 2 & 118 & 118 & 1.66 & 0.20 & OR $1.48(0.25$ to 8.79$)$ & 0.67 \\
\hline 3-year OS & 5 & 619 & 504 & 7.42 & 0.12 & HR 0.89 (0.66 to 1.19$)$ & 0.42 \\
\hline 3-year DFS & 3 & 197 & 202 & 0.39 & 0.82 & HR 1.28 (0.68 to 2.40$)$ & 0.44 \\
\hline 5-year OS & 4 & 366 & 376 & 2.27 & 0.52 & HR 1.10 (0.77 to 1.58$)$ & 0.60 \\
\hline 5-year DFS & 5 & 197 & 202 & 1.08 & 0.58 & HR 1.12 (0.63 to 1.98$)$ & 0.70 \\
\hline
\end{tabular}

RCT, randomized controlled trial; 95\% CI, 95\% confidence interval; WMD, weighted mean difference; OR, odds ratio; CRM, circumferential resection margin; RR, relative risk; OS, overall survival; DFS, disease-free survival; HR, hazard ratio.

effect of colorectal cancer surgery and CRM has notable significance for the evaluation of the prognosis of colorectal cancer surgery $(24,25)$. Huang et al (26) and certain studies performed in China $(27,28)$ have reported that there was no significant difference in lymph node dissection and other indicators between laparoscopic and laparotomy of colorectal cancer. The results of the meta-analysis in the present study showed that there was no statistical difference in the number of dissected lymph nodes $(\mathrm{P}=0.88)$ or the CRM-positive rate $(\mathrm{P}=0.86)$. Compared to traditional open surgery, concern is focused on the long-term survival rate of colorectal cancer patients following laparoscopic surgery. The results showed no statistical difference in 3- or 5-year OS and 3-or 5-year DFS between the two groups $(\mathrm{P}>0.05)$.
The rectum is located in the pelvic cavity and colorectal cancer surgery inevitably has a certain impact on the urogenital system. Quah et al (29) and Jayne et al (30) have reported that the impact of laparoscopic surgery of colorectal cancer on male sexual function was more evident compared to traditional open surgery, but there was no significant difference for the impact on female sexual function and on bladder function. In the present study, the meta-analysis results showed that there was no statistical difference in the incidence of urinary retention between the two groups. The reason for the impact on male sexual function remains unclear and whether this is due to iatrogenic damage of the pelvic autonomic nerves caused by laparoscopic surgery lacks relevant evidence. The surgical time of laparoscopic surgery of colorectal cancer is longer 
A

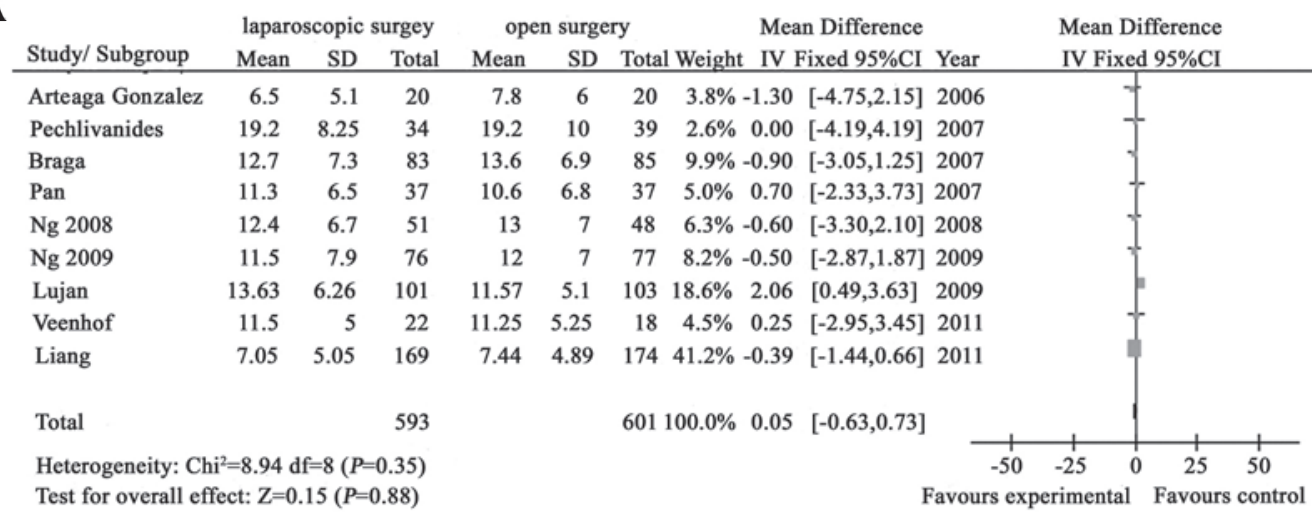

B

\begin{tabular}{|c|c|c|c|c|c|c|c|c|}
\hline \multirow[b]{2}{*}{ Study/ Subgroup } & \multicolumn{2}{|c|}{ laparoscopic surgery } & \multicolumn{2}{|c|}{ open surgery } & \multicolumn{3}{|c|}{ Risk Ratio } & \multirow{2}{*}{$\begin{array}{c}\text { Risk Ratio } \\
\text { M-H Fixed } 95 \% \mathrm{CI}\end{array}$} \\
\hline & Events & Total & Events & Total & Weight & M-H Fixed 95\%CI & Year & \\
\hline Guillou & 30 & 193 & 14 & 97 & $55.4 \%$ & $1.08[0.60,1.93]$ & 2005 & \\
\hline Braga & 1 & 83 & 2 & 85 & $5.9 \%$ & $0.51[0.05,5.54]$ & 2007 & \\
\hline $\mathrm{Ng} 2008$ & 3 & 51 & 2 & 48 & $6.1 \%$ & $1.41[0.25,8.09]$ & 2008 & \\
\hline $\mathrm{Ng} 2009$ & 2 & 76 & 1 & 77 & $3.0 \%$ & $2.03[0.19 .21 .88]$ & 2009 & \\
\hline Lujan & 4 & 101 & 3 & 103 & $8.8 \%$ & $1.36[0.31,5.92]$ & 2009 & \\
\hline Kang & 5 & 170 & 7 & 170 & $20.8 \%$ & $0.71[0.23,2.21]$ & 2010 & \\
\hline Total & 45 & 674 & 29 & 580 & $100 \%$ & $1.04[0.66,1.64]$ & & \\
\hline \multicolumn{7}{|c|}{ Heterogeneity: $\mathrm{Chi}^{2}=1.33, \mathrm{df}=5(P=0.93)$} & + & \\
\hline \multicolumn{7}{|c|}{ Test for overall effect: $Z=0.18(P=0.86)$} & $\begin{array}{r}0.005 \\
\text { iavours }\end{array}$ & $\begin{array}{ccr}0.1 & 1 & 10 \\
\text { kperimental } & \text { Favou }\end{array}$ \\
\hline
\end{tabular}

C

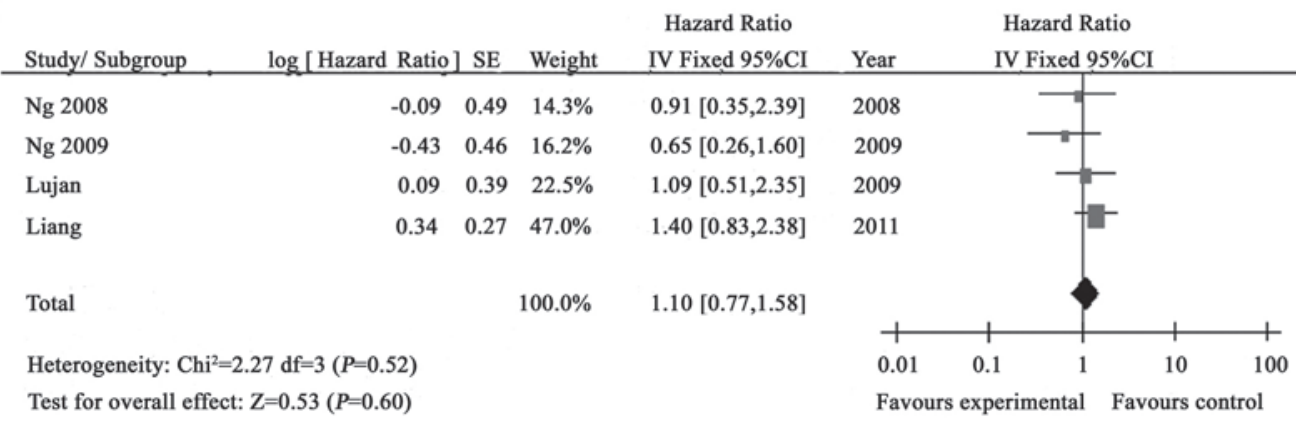

Figure 1. Meta-analysis results between laparoscopic and open surgery treatment of rectal cancer. There were no significant differences (A) in the number of lymph nodes and (B) circumferential-resection margin positive ratios for the two groups (P>0.05). (C) Laparoscopic surgery can not improve the overall survival and disease-free survival, compared to laparotomy ( $\mathrm{P}>0.05)$. SD, standard deviation; $95 \% \mathrm{CI}$, $95 \%$ confidence interval; SE, standard error.

compared to laparatomy, and laparoscopic surgery has higher requirements for surgeons. The laparoscopic surgery time in different areas are shown in Table III, which has clear heterogeneity, indicating that the proficiency of laparoscopic surgeons in various areas was different. However, the surgeons undergo rigorous training and development for a period of time, which improves the surgical procedure. Bujko et al (31) reported in a review, which included $10 \mathrm{RCTs}$ and the statistical analysis of 4,596 colerectal cancer patients, that preoperative radiotherapy and chemotherapy could not improve the anal preservation rate and therefore, whether the anus could be preserved depended on the tumor characteristics and the individual techniques of the surgeon. This indicates higher requirements for surgeons, including improved surgical techniques that enhance the life quality of patients and employing the principle of the non-neoplasma technique during surgery. This technique is the same as in the open surgery, which involves the injection of chemotherapy drugs in the intestinal cavity, the flushing and soaking of the basin with warm distilled water, the placement of a protective cover in the incision and avoiding the 'chimney effect'.

The method for the quality evaluation with digital score that was used previously may cause bias (32). The scoring method was not used in the present study to evaluate RCTs, however 'The Cochrane Collaboration's tool for assessing risk of bias' from the Cochrane Handbook and the method recommended by Lundh and Gøtzsche (32) were applied to evaluate the seven indicators generated by random sequence. The critical points of evaluation of the RCT methodology were utilized to reduce potential bias. 
The present study has certain limitations. The total mesorectal excision (TME) for the treatment of colorectal cancer has been recognized previously (33), however, the included RCTs did not clearly state TME as a surgical approach. Considering that TME may be applied in the implementation of the surgery and that the study did not perform subgroup analysis, there may be bias.

In conclusion, laparoscopic surgery of colorectal cancer is quicker in the recovery of intestinal peristalsis and the time for consuming liquid food compared to traditional open surgery, however, there was no significant difference in the tumor resection effects, including lymph node dissection, CRM and long-term survival rate. Therefore, laparoscopic surgery can be used as a standard procedure for the treatment of colorectal cancer and it should be promoted for clinical practice.

\section{Acknowledgements}

The present study was supported by the National Natural Science Foundation of China (grant nos. 81172362 and 81101874) and the Science and Technology Projects of Shaanxi Province (grant no. 2013KTCQ03-08).

\section{References}

1. Siegel R, Desantis C and Jemal A: Colorectal cancer statistics, 2014. CA Cancer J Clin 64: 104-117, 2014

2. Buunen M, Veldkamp R, Hop WC, et al; Colon Cancer Laparoscopic or Open Resection Study Group: Survival after laparoscopic surgery versus open surgery for colon cancer: long-term outcome of a randomised clinical trial. Lancet Oncol 10: 44-52, 2009.

3. Jayne DG, Thorpe HC, Copeland J, Quirke P, Brown JM and Guillou PJ: Five-year follow-up of the Medical Research Council CLASICC trial of laparoscopically assisted versus open surgery for colorectal cancer. Br J Surg 97: 1638-1645, 2010.

4. Higgins JPT and Green S (eds): Cochrane Handbook for Systematic Reviews of Interventions. Version 5.1.0 [updated March 2011]. The Cochrane Collaboration, 2011. Available from www.cochrane-handbook.org.

5. Hozo SP, Djulbegovic B and Hozo I: Estimating the mean and variance from the median, range, and the size of a sample. BMC Med Res Methodol 5: 13, 2005.

6. Tierney JF, Stewart LA, Ghersi D, Burdett S and Sydes MR: Practical methods for incorporating summary time-to-event data into meta-analysis. Trials 8: 16, 2007.

7. Jayne DG, Guillou PJ, Thorpe H, et al; UK MRC CLASICC Trial Group: Randomized trial of laparoscopic-assisted resection of colorectal carcinoma: 3-year results of the UK MRC CLASICC Trial Group. J Clin Oncol 25: 3061-3068, 2007.

8. Guillou PJ, Quirke P, Thorpe H, et al; MRC CLASICC trial group: Short-term endpoints of conventional versus laparoscopic-assisted surgery in patients with colorectal cancer (MRC CLASICC trial): multicentre, randomised controlled trial. Lancet 365: 1718-1726, 2005.

9. Araujo SE, da Silva eSousa AH Jr, de Campos FG, et al: Conventional approach $\mathrm{x}$ laparoscopic abdominoperineal resection for rectal cancer treatment after neoadjuvant chemoradiation: results of a prospective randomized trial. Rev Hosp Clin Fac Med Sao Paulo 58: 133-140, 2003.

10. Zhou ZG, Hu M, Li Y, et al: Laparoscopic versus open total mesorectal excision with anal sphincter preservation for low rectal cancer. Surg Endosc 18: 1211-1215, 2004.

11. Arteaga González I, Díaz Luis H, Martín Malagón A, López-Tomassetti Fernández EM, Arranz Duran J and Carrillo Pallares A: A comparative clinical study of short-term results of laparoscopic surgery for rectal cancer during the learning curve. Int J Colorectal Dis 21: 590-595, 2006.

12. Braga M, Frasson M, Vignali A, Zuliani W, Capretti G and Di Carlo V: Laparoscopic resection in rectal cancer patients: outcome and cost-benefit analysis. Dis Colon Rectum 50: 464-471, 2007
13. Pechlivanides G, Gouvas N, Tsiaoussis J, et al: Lymph node clearance after total mesorectal excision for rectal cancer: laparoscopic versus open approach. Dig Dis 25: 94-99, 2007.

14. Pan YF, Zhang XH, Jia XJ, et al: Laparoscopic abdominoperineal resection for low rectal cancer. Zhonghua Wei Chang Wai Ke Za Zhi 10: 253-256, 2007 (In Chinese).

15. Ng SS, Leung KL, Lee JF, Yiu RY, Li JC, Teoh AY and Leung WW: Laparoscopic-assisted versus open abdominoperineal resection for low rectal cancer: a prospective randomized trial. Ann Surg Oncol 15: 2418-2425, 2008.

16. Lujan J, Valero G, Hernandez Q, Sanchez A, Frutos MD and Parrilla P: Randomized clinical trial comparing laparoscopic and open surgery in patients with rectal cancer. Br J Surg 96: 982-989, 2009.

17. Ng SS, Leung KL, Lee JF, et al: Long-term morbidity and oncologic outcomes of laparoscopic-assisted anterior resection for upper rectal cancer: ten-year results of a prospective, randomized trial. Dis Colon Rectum 52: 558-566, 2009.

18. Kang SB, Park JW, Jeong SY, et al: Open versus laparoscopic surgery for mid or low rectal cancer after neoadjuvant chemoradiotherapy (COREAN trial): short-term outcomes of an open-label randomised controlled trial. Lancet Oncol 11: 637-645, 2010.

19. Liang X, Hou S, Liu H, et al: Effectiveness and safety of laparoscopic resection versus open surgery in patients with rectal cancer: a randomized, controlled trial from China. J Laparoendosc Adv Surg Tech A 21: 381-385, 2011.

20. Veenhof AA, Sietses C, von Blomberg BM, et al: The surgical stress response and postoperative immune function after laparoscopic or conventional total mesorectal excision in rectal cancer: a randomized trial. Int J Colorectal Dis 26: 53-59, 2011.

21. Hawk ET, Limburg PJ and Viner JL: Epidemiology and prevention of colorectal cancer. Surg Clin North Am 82: 905-941, 2002.

22. Lin JZ and Pan ZZ: Disputes about surgical treatment of colorectal liver metastasis. Zhonghua Wei Chang Wai Ke Za Zhi 16: 714-717, 2013 (In Chinese).

23. Chand M, Bhoday J, Brown G, Moran B and Parvaiz A: Laparoscopic surgery for rectal cancer. J R Soc Med 105: 429-435, 2012.

24. Luna-Pérez P, Bustos-Cholico E, Alvarado I, Maffuz A, Rodríguez-Ramírez S, Gutiérrez de la Barrera $M$ and Labastida S: Prognostic significance of circumferential margin involvement in rectal adenocarcinoma treated with preoperative chemoradiotherapy and low anterior resection. J Surg Oncol 90: 20-25, 2005.

25. Adam IJ, Mohamdee MO, Martin IG, et al: Role of circumferential margin involvement in the local recurrence of rectal cancer. Lancet 344: 707-711, 1994.

26. Huang MJ, Liang JL, Wang H, Kang L, Deng YH and Wang JP: Laparoscopic-assisted versus open surgery for rectal cancer: a meta-analysis of randomized controlled trials on oncologic adequacy of resection and long-term oncologic outcomes. Int J Colorectal Dis 26: 415-421, 2011.

27. Ren KY: Comparison of short-term efficacy between laparoscopic and open resection of colorectal cancer. Chin J Gen Surg 22: 374-376, 2013.

28. Chen XX, Zhou YC, Zhang ZM, Wei ZX, Huang KW, Zhou WM and Long XF: Comparative study on laparoscopic and open resection for low rectal cancer. Chin J Gen Surg 20: 356-359, 2011.

29. Quah HM, Jayne DG, Eu KW and Seow-Choen F: Bladder and sexual dysfunction following laparoscopically assisted and conventional open mesorectal resection for cancer. Br J Surg 89: 1551-1556, 2002.

30. Jayne DG, Brown JM, Thorpe H, Walker J, Quirke P and Guillou PJ: Bladder and sexual function following resection for rectal cancer in a randomized clinical trial of laparoscopic versus open technique. Br J Surg 92: 1124-1132, 2005.

31. Bujko K, Kepka L, Michalski W and Nowacki MP: Does rectal cancer shrinkage induced by preoperative radio(chemo)therapy increase the likelihood of anterior resection? A systematic review of randomised trials. Radiother Oncol 80: 4-12, 2006.

32. Lundh A and Gøtzsche PC: Recommendations by Cochrane Review Groups for assessment of the risk of bias in studies. BMC Med Res Methodol 8: 22, 2008.

33. Yao XQ, Ou-Yang ZA, Lin F, Qing SH, Huang XC and Zhang SZ: Affecting factors of prognosis for total mesorectal excision of rectal cancer. Chin J Clin Anatomy 23: 547-549, 2005 (In Chinese). 